Research Article

\title{
Fabrication and Study on Thermal Conductivity, Electrical Properties, and Mechanical Properties of the Lightweight Carbon/Carbon Fiber Composite
}

\author{
Bo Tang, ${ }^{1,2}$ Ying Wang, ${ }^{2,3}$ Jinhong Yu $\mathbb{D},{ }^{4}$ Ke Yang, ${ }^{5}$ Yonggen Lu $\mathbb{D}^{1},{ }^{1}$ Xinfeng Wu $\mathbb{D},{ }^{2,3}$ \\ Kai Sun, ${ }^{3}$ Xiaofeng Li, ${ }^{3}$ Runhua Fan, ${ }^{3}$ Danda Shi, ${ }^{3}$ and Wei Shao ${ }^{3}$ \\ ${ }^{1}$ State Key Laboratory for Chemical Fibers Modification and Polymer Materials, College of Materials Science and Engineering, \\ Donghua University, Shanghai 201620, China \\ ${ }^{2}$ Hangzhou Vulcan New Materials Technology Co., Ltd., Hangzhou 311255, China \\ ${ }^{3}$ College of Ocean Science and Engineering, Shanghai Maritime University, Shanghai 201306, China \\ ${ }^{4}$ Key Laboratory of Marine Materials and Related Technologies, \\ Zhejiang Key Laboratory of Marine Materials and Protective Technologies, \\ Ningbo Institute of Materials Technology \& Engineering, Chinese Academy of Sciences, Ningbo 315201, China \\ ${ }^{5}$ School of Materials Science and Engineering, Central South University, Changsha 410083, China
}

Correspondence should be addressed to Jinhong Yu; yujinhong@nimte.ac.cn, Yonggen Lu; yglu@dhu.edu.cn, and Xinfeng Wu; xfwu@shmtu.edu.cn

Received 2 May 2020; Accepted 23 July 2020; Published 17 August 2020

Academic Editor: Nenad Ignjatović

Copyright ( 2020 Bo Tang et al. This is an open access article distributed under the Creative Commons Attribution License, which permits unrestricted use, distribution, and reproduction in any medium, provided the original work is properly cited.

In this paper, lightweight carbon/carbon fiber composite thermal field insulation materials were fabricated by the process method of long carbon fiber airflow netting-needle punching forming felt-resin impregnation-molding curing-high-temperature carbonization and graphitization. The microscopic morphology, conductivity, bending strength, and thermal conductivity of carbon/ carbon fiber composites were measured by using the scanning electron microscope (SEM), four probes, electronic universal testing machine, and thermal analyzer. The results show that the long carbon fiber in the carbon/carbon fiber composite forms a three-dimensional structure of $X-Y-Z$ with a density of $0.16 \pm 0.02 \mathrm{~g} / \mathrm{cm}^{3}$, which makes the composite material have excellent thermal insulation performance at high temperature, and the conductivity is $1452.4 \mathrm{~S} / \mathrm{m}$ (plane direction) and $182.8 \mathrm{~S} / \mathrm{m}$ (perpendicular to the plane direction), the compressive strength is $0.2 \mathrm{MPa}$ (plane direction) and $1.31 \mathrm{MPa}$ (perpendicular to the plane direction), the bending strength is $0.24 \mathrm{MPa}$ (plane direction) and $1.1 \mathrm{MPa}$ (perpendicular to the plane direction), and the thermal conductivity is $0.076 \mathrm{~W} /(\mathrm{mK})\left(25^{\circ} \mathrm{C}\right)$ and $0.17 \mathrm{~W} /(\mathrm{mK})\left(1200^{\circ} \mathrm{C}\right)$, respectively. The above process methods and test results will provide the application of the carbon/carbon fiber composite in the solar polysilicon furnace, single crystal silicon furnace, semiconductor furnace, sapphire furnace, fiber drawing furnace, and high-end metallurgical heat treatment furnaces, as well as applications in other high-temperature insulation environments, and also provide some suggestions in these insulation applications.

\section{Introduction}

Most of the growth of the silicon crystal, silicon carbide crystal, and sapphire crystal needs to be carried out at a temperature higher than $1500^{\circ} \mathrm{C}$. At this temperature, metal materials and alloy materials have melted, while ceramic materials cannot meet the actual needs because of the difficulties in forming large parts and high cost. Carbon fiber is used in the field of high-temperature insulation, especially in the field of crystal growth, because of its excellent mechanical properties, high temperature resistance (higher than $2000^{\circ} \mathrm{C}$ in inert atmosphere) $[1,2]$, and heat preservation performance. In addition, the molding method of carbon/carbon fiber composite materials is relatively easy to 
achieve. Carbon/carbon fiber composites can be divided into low-density carbon/carbon fiber composites $\left(0.1-0.4 \mathrm{~g} / \mathrm{cm}^{3}\right)$ [3-5] and high-density carbon/carbon materials $\left(1.0-1.8 \mathrm{~g} / \mathrm{cm}^{3}\right)[6-9]$. This paper focuses on low-density carbon/carbon fiber composites. Low-density carbon/carbon fiber insulation composites are widely used in the single crystal silicon furnace, solar polysilicon furnace, high-end metallurgical heat treatment furnace, sapphire furnace, fiber drawing furnace, and semiconductor furnace, as well as applications in other high-temperature insulation environments, due to their excellent high-temperature insulation performance, high temperature resistance, low impurity content, and high strength [10-15].

Lightweight carbon/carbon fiber composites can be prepared from carbon fiber materials (or fiber felts) by impregnating resin-molding curing-high temperature graphitization. Lightweight carbon/carbon fiber composites can be divided into two categories according to the fiber length, and the two categories of molding methods are also different. The two categories are (a) short-cut carbon/carbon fiber composite (fiber lengths in the order of millimeters, such as $3-5 \mathrm{~mm}$ ) and (b) long-fiber carbon/carbon fiber composite (fiber lengths in centimeters, such as $10 \mathrm{~cm}-15 \mathrm{~cm}$ ) [16-18]. (a) Short-cut carbon/carbon fiber composite is represented by SGL group of Germany and Morgan Corporation of the United States. (a) The short-cut carbon/carbon fiber composite is mainly prepared by impregnating phenolic resin with short-cut fiber, pouring into the mold, molding, and graphitization at high temperature. The method has the advantages that the preparation process is relatively short, the felt is not prepared, and the cost is relatively low. Its disadvantage is that the fiber in the material presents $X-Y-Z$ isotropy, and the $Z$-direction fiber is easy to transfer heat, resulting in poor insulation performance. At the same time, because the fiber is short, the fiber is easy to fall off, the dust is relatively large, and it is easy to pollute the thermal field environment. (b) Long-fiber carbon/carbon fiber composite is represented by the product of Kureha Chemical of Japan. Long-fiber carbon/carbon fiber composite is prepared by long-fiber felt impregnationmolding curing-graphitization at high temperature. Compared with the short-fiber carbon/carbon fiber composite, long-fiber carbon/carbon fiber composite has more felting process. The cost of the preparation process of the long-fiber carbon/carbon fiber composite increases due to the felting process, but it also brings advantages in performance. The carbon/carbon fiber composite prepared by the long-fiber method has an $X-Y-Z$ anisotropic structure, the fiber arrangement is mainly in the $X-Y$ plane direction, and the $Z$ direction fiber rarely plays only a reinforcing role. This anisotropic structure makes the composite material have better thermal insulation performance. In addition, the fiber length is longer, and the dust is less, which is not easy to pollute the thermal field environment. Compared with the traditional carbon fiber felt materials, lightweight carbon/ carbon fiber composites have higher mechanical strength, easy installation, high temperature steam erosion resistance, and long service life due to the adhesion of carbon to carbon fiber felt.
In the traditional process of preparing the lightweight carbon/carbon fiber composite with the long fiber, the carbon fiber felt is usually made by weaving the preoxidized and then carbonizing at high temperature. The shrinkage of the carbon fiber felt is relatively large, which is easy to make the carbon/carbon fiber composite layered. In addition, the traditional method has a long process, increased uncontrollable factors, and low yield. Our team cooperated with Hangzhou Vulcan New Materials Technology Co., Ltd. to solve a series of technological problems and formed a set of innovative preparation process of high temperature resistance, heat preservation, and lightweight carbon/carbon fiber composite. The innovation lies in the following two points. (a) Long carbon fiber is used to prepare lightweight carbon/carbon fiber composite, and the thermal insulation performance of the prepared carbon/carbon fiber composite is better than that of the short-cut fiber. (b) The direct use of carbon fiber airflow netting-needle forming felt process instead of preoxidized fiber airflow netting-needle punching-carbonization process reduces the process steps and avoids product shrinkage due to carbonization.

One of the most important properties of the carbon/ carbon fiber composite in the use of high-temperature furnaces is the thermal insulation property, so it is necessary to study the thermal conductivity of the carbon/carbon fiber composite based on the previous research [19]. In our previous research, the thermal conductivity of the lightweight carbon/carbon fiber composite was studied by means of the heat flow meter method, and its mechanism was studied. In this paper, the thermal conductivity of the lightweight carbon/carbon fiber composite through the guarded hot plate apparatus will be studied. At the same time, the degree of graphitization of the carbon/carbon fiber composite is related to the high temperature resistance of the carbon/carbon fiber composite. This paper will measure the graphitization of the material through the study of electrical conductivity. The mechanical properties of the lightweight carbon/carbon fiber composite are related to the dimensional stability of the carbon/carbon composite, which is related to the thermal field stability of the high-temperature furnace. Therefore, the mechanical properties of the lightweight carbon/carbon fiber composite have also been studied. The effects of the $X-Y-Z$ three-dimensional structure on the thermal conductivity, electrical conductivity, and mechanical properties of the lightweight carbon/carbon fiber composite were also studied. At the same time, the mechanism of influence was also studied. It is expected to provide some advice for the application of high-temperature equipment such as crystal growth and high-temperature heat treatment.

\section{Experimental}

2.1. Materials. Phenolic resin: model PF-5408, viscosity: $450-750\left(25^{\circ} \mathrm{C}, \mathrm{cP}\right)$, solid content: $65 \%$, free phenol: $9.5 \%-$ $11.8 \%$, and moisture: $2.5 \%-4.0 \%$, Jinan Shengquan Group Co., Ltd.

Carbon fiber: model SYT45, 12K, Zhongfu Shenying Carbon Fiber Co., Ltd. 
Absolute ethanol: AR, Sinopharm Chemical Reagent Co., Ltd.

2.2. Sample Preparation. Figure 1 shows the schematic diagram of the preparation process of the carbon/carbon fiber composite. The preparation process includes carbon fiber long-fiber cutting-airflow netting-needle punching forming felt-resin impregnation-molding curing-high temperature carbonization and graphitization, which will be explained in the following.

(a) Airflow netting: the long fibers $(100 \mathrm{~mm}-150 \mathrm{~mm})$ (Figure 1(a)) are made into a web embryo by airflow netting forming technology. The fibers in the web embryo are arranged randomly and disorderly to form an $X-Y$ structure. There is almost no binding force between the fibers, and it is very easy to disperse.

(b) Needle punching forming felt: part of the carbon fibers on the $X-Y$ plane is transformed into carbon fibers in the $Z$ direction through the needle punching forming method [20] (Figure 1(b)). The existence of $Z$-up fibers increases the binding force between the fiber layers, making the fiber felt a soft felt with the $X-Y-Z$ structure. There is no fiber shrinkage phenomenon in the process of airflow forming, so the performance of the carbon fiber soft felt is better than that of the preoxidized felt. At the same time, the type, diameter, and three-dimensional structure of the carbon fiber used in the soft felt will have an impact on the thermal insulation performance of the soft felt. The long carbon fiber alignment anisotropy $X-Y$ plane to $Z$-direction fiber fraction ratio is $(50-250): 1$. The carbon fiber soft felt body weight is $500 \mathrm{~g} / \mathrm{m}^{2}-900 \mathrm{~g} / \mathrm{m}^{2}$, the carbon fiber felt thickness is $10 \mathrm{~mm}$, and the carbon fiber felt width is $>1500 \mathrm{~mm}$.

(c) Resin impregnation: phenolic solution and ethanol are mixed to form phenolic/ethanol solution in order to fully impregnate the carbon fiber soft felt (Figure 1(c)). The solid content of the phenolic solution is controlled to $30-40 \%$. The mass ratio of the carbon fiber soft felt to the phenolic resin is 1 : $1-1.5$. The spray immersion must be uniform. After spray impregnation, the ethanol resin must be recovered by drying, and the ethanol content of the impregnated felt should be controlled below $5 \%$.

(d) Molding curing: the soft felt/phenolic composite is pressure-cured (Figure 1(d)). The curing temperature is from room temperature to $175^{\circ} \mathrm{C}$, and the curing time is 3 to 6 hours. The force is $30 \mathrm{t}$.

(e) Carbonization and graphitization: the cured soft felt/ phenolic composite is carbonized and graphitized in a high-temperature furnace to remove the phenolic resin (Figure 1(e)). In the process of high-temperature carbonization, the phenolic resin decomposes into carbon, and the composite material shrinks. The thickness of the composite material can be controlled by the mold. The temperature will rise from the room temperature step to $2400^{\circ} \mathrm{C}$, and the air pressure will be controlled at $10-8000 \mathrm{~Pa}$. The prepared $\mathrm{C} / \mathrm{CF}$ composite size can reach $1500 \mathrm{~mm}^{*} 1500 \mathrm{~mm}$. The thickness can be $40 \mathrm{~mm}$, $45 \mathrm{~mm}$, and $50 \mathrm{~mm}$ as needed.

\subsection{Characterization}

2.3.1. Field Emission Scanning Electron Microscope (SEM). The internal microscopic morphology of the carbon/carbon fiber composite was characterized by scanning electron microscopy of model S-2150 (Hitachi Corp., Japan). The SEM image includes scanning in both directions parallel to the plane direction and perpendicular to the plane direction.

2.3.2. Thermal Conductivity Test. The thermal conductivity of carbon/carbon fiber composites was tested by the guarded hot plate method according to ISO 8302:1991 IDT (Thermal insulation-Determination of steady-state thermal resistance and related properties-Guarded hot plate apparatus). The sample size was $300 \mathrm{~mm}^{*} 300 \mathrm{~mm}^{*} 50 \mathrm{~mm}$. The density of the sample was $0.16 \mathrm{~g} / \mathrm{cm}^{3}$. The thermal conductivity was measured at $25^{\circ} \mathrm{C}$ and $1200^{\circ} \mathrm{C}$.

2.3.3. Volume Resistivity Test. The volume resistivity of the carbon/carbon fiber composite was tested using the fourprobe method. Schematic diagram of resistivity test by the four-probe method is shown in Figure 2. The current I is supplied by a constant current source (Agilent E3633A), and the voltage is measured using a Hioki data logger (8421-51). Carbon/carbon fiber block is sandwiched between two thick copper sheets $(200 \mu \mathrm{m})$, and the current terminals are, respectively, connected to two opposite copper sheets. The diameter of the voltage probe is $0.3 \mathrm{~mm}$. The test is divided into two directions (plane direction and perpendicular to the plane direction). Figure 3 shows the carbon/carbon fiber composite resistivity test directions. Three sets of data are measured in each direction.

The resistance of the tested carbon/carbon fiber composite can be measured by the four-probe machine. The resistance formula is $R=\rho L / S$, where $R$ is the resistance $(\Omega)$, $L$ is the material length $(\mathrm{m}), S$ is the electrode contact area $\left(\mathrm{m}^{2}\right)$, and $\rho$ is the resistivity $(\Omega \bullet \mathrm{m})$. The electrical conductivity $(\sigma)$ can be calculated by the formula $\sigma=1 / \rho=L / R S$; the unit of electrical conductivity is $S / \mathrm{m}$.

2.3.4. Mechanical Performance Test. The compressive strength and the bending strength of carbon/carbon fiber composites were tested by a SANS microcomputer control electronic universal testing machine (model CMT4804, Shenzhen Xinsansi Material Technology Co., Ltd) according to ISO844:2004 (Rigid Cellular Plastics-Determination of Compression Properties) and ISO 1209-2:2004 (Rigid Cellular Plastics-Determination of Flexural Properties-Part 2: Determination of Flexural Strength and Apparent Flexural Modulus of Elasticity). The size of the compression sample is $50 \mathrm{~mm} * 50 \mathrm{~mm} * 50 \mathrm{~mm}$, and the number of test samples is 10,5 


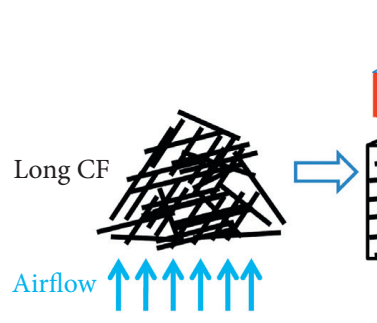

(a)

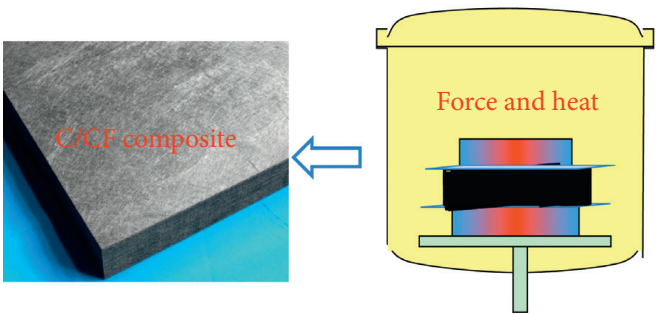

(e)

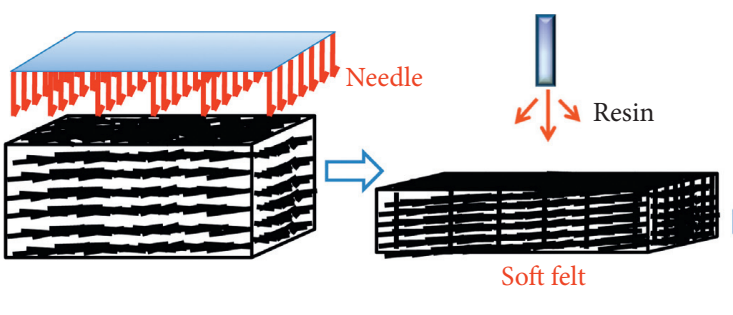

(c)

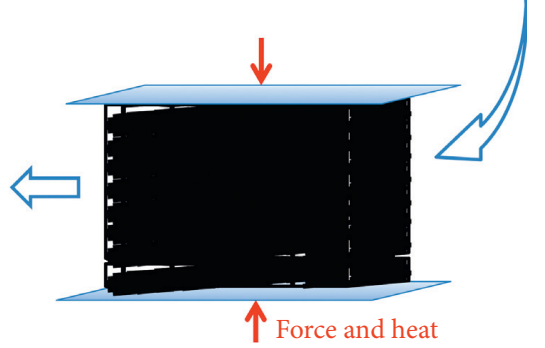

(d)

FiguRE 1: Schematic diagram of the preparation process of the carbon/carbon fiber composite. (a) Airflow netting. (b) Needle punching forming felt. (c) Resin impregnation. (d) Molding curing. (e) Carbonization and graphitization.

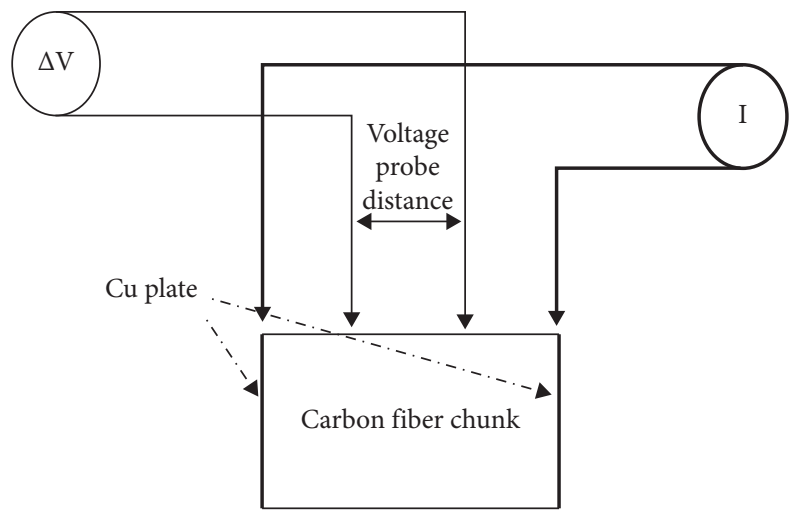

FIGURE 2: Schematic diagram of resistivity test by the four-probe method.

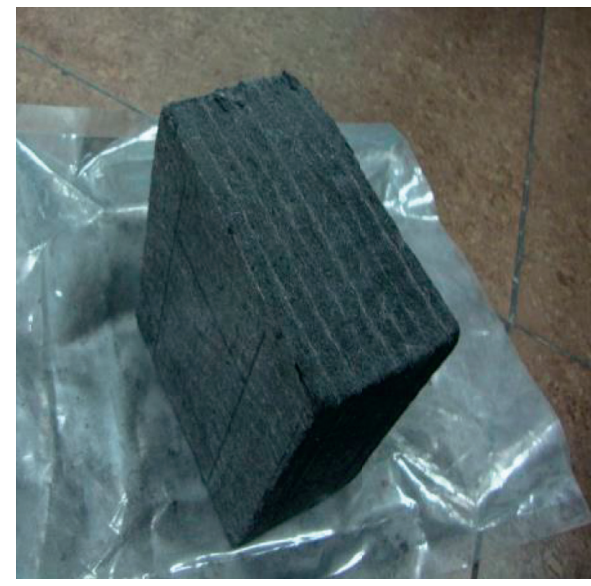

(a)

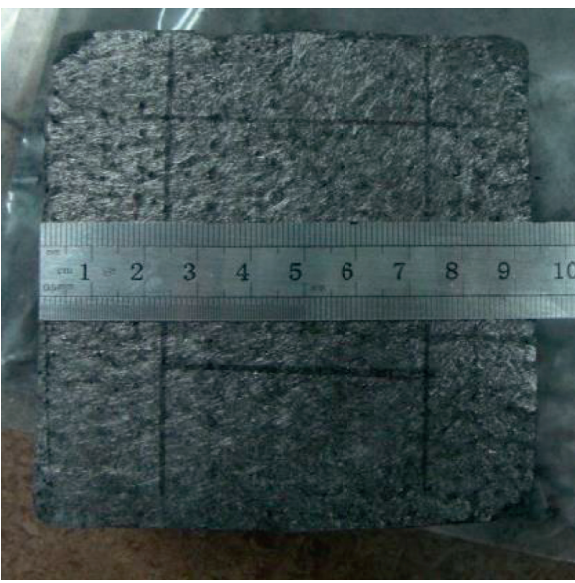

(b)

FIGURE 3: Carbon/carbon fiber composite resistivity test directions: (a) perpendicular to the plane direction; (b) plane direction. 
for side compression and 5 for forward compression. At the same time, in order to study the recoverability of the $Z$ direction, three compression tests were repeated on the same sample to see the change of compressive strength, and the mechanism of compression failure was studied. The dimensions of the bending samples are $120 \mathrm{~mm}^{*} 25 \mathrm{~mm}^{*} 20 \mathrm{~mm}$ (front bend) and $120 \mathrm{~mm}^{*} 20 \mathrm{~mm}^{*} 25 \mathrm{~mm}$ (side bend). Both the compression and the bending rates are $10 \mathrm{~mm} / \mathrm{min}$.

\section{Results and Discussion}

3.1. Characterization of Carbon/Carbon Fiber Composites. Figure 4 shows carbon/carbon fiber composites. It can be seen from Figure 4(a) that the size of the carbon fiber composite plate can be $1500 \mathrm{~mm}^{*} 1500 \mathrm{~mm}$ or even larger according to the size of carbon fiber felt used and the control of mold. The carbon/carbon fiber composite plate surface is flat, which can achieve seamless heat preservation in the surface and improve the heat preservation effect when preparing large heat preservation field materials. It can be seen from the profile material in Figure 4(b) that the longfiber carbon/carbon fiber composite can not only be used as the plate but also be fully competent for the profile material, and the size of the profile material can be very accurate. In addition, the surface of the profile material can also be treated with special coating, such as graphite coating, Hfbased antioxidation coating, silicon carbide coating, boron nitride coatings, and other coatings [21-31].

Figure 4(c) shows the cross section of the carbon/carbon fiber composite plate. From Figure 4(c), it can be seen that carbon fibers are distributed layer by layer, and some vertical fibers are caused by needling during the forming process. The layered structure is composed of carbon fiber felts in the $X$ - $Y$ plane, and the Z-direction fibers perpendicular to the $X$ $Y$ plane are formed by needling. Finally, the carbon/carbon fiber composite forms an $X-Y-Z$ three-dimensional structure. The fiber structure of the $X-Y$ plane is loose, and the existence of $Z$-direction needled fibers can make the loose $X$ $Y$ fibers form a tight structure. In Figure 4(d), ring-shaped parts, the layered structure of the carbon/carbon fiber composite can be seen very clearly. The continuous fiber felt ensures that the ring carbon/carbon fiber composite becomes a whole so that the carbon fibers are closely combined, thus having high strength. The $X-Y-Z$ threedimensional microstructure of the carbon/carbon fiber composite will be shown in the SEM images.

The density of the carbon/carbon fiber composite is $0.16 \pm 0.02 \mathrm{~g} / \mathrm{cm}^{3}$. It is much lower than the high-density carbon/carbon composite. This kind of low-density network felt structure gives the material superior heat preservation performance, which will be described next in detail.

\subsection{Microstructure Characterization and Thermal Conduc-} tivity Analysis of Carbon/Carbon Fiber Composites. Figure 5 shows the SEM images of carbon/carbon fiber composites. Figures 5(a) and 5(b) show the microscopic topography of the carbon/carbon fiber composite inner surface which is parallel to the laminate. Figures 5(c) and 5(d) show the microscopic topography of the carbon/carbon fiber composite section which is vertical to the laminate. It can be seen from Figures 5(a) and 5(b) that the carbon fibers are disorderly overlapped, and some overlapped positions are adhered in the red circle (Figure 5(b)). The adhesion position is due to the residual carbon material after graphitization of the phenolic resin impregnated. This can enhance the strength of the felt material so that the felt is not easy to loosen, and the shape is not easy to deform. That is to say, as a bonded carbon structure, it can maintain the stability of the overall structure of the lightweight carbon/ carbon fiber composite. The bonded carbon structure can make the lightweight carbon/carbon fiber composite have certain mechanical strength and play an important role in strengthening, which will be described in the following chapters on the compressive strength and the bending strength. From Figures 5(c) and 5(d), it can be seen that carbon fibers are arranged in an orderly and staggered way one by one, which is caused by the uniform fall of carbon fiber felt layer by layer during the air flow forming process in the preparation process. In addition, it can be seen that each layer of the carbon fiber is staggered with each other, but almost every layer is perpendicular to the section, and there is almost no carbon fibers parallel to the section. In the yellow circle in Figure 5(c), it can be seen that there is a bunch of carbon fibers parallel to the $Z$ direction, which is produced by acupuncture during the production process, which is conducive to improving the strength between layers. In the red circle in Figure 5(d), it can be seen that some fibers in the same layer are adhered, which is conducive to improving the strength of the same carbon fiber layer. In addition, carbon fibers are stacked very closely with few gaps. Under high-temperature conditions, they can prevent high temperature air flow into the composite and prevent the occurrence of thermal convection. This creates a very good insulation structure.

This insulation structure can be explained in Figure 6. Figure 6 shows the heat transfer model in the carbon/carbon fiber composite. Heat transfer includes heat convection, heat radiation, and heat conduction [32-34]. From Figure 5(c), the phenomenon of thermal convection can be prevented due to the close stacking of carbon fibers with few gaps. Even if there are gaps, thermal convection needs to go through a long zigzag transmission route for convection, and the heat transferred by thermal convection is relatively small. For the phenomenon of heat conduction, it can be seen from Figure 5(c) that each layer of the carbon fiber is almost perpendicular to the profile. In each layer of the carbon fiber, heat conduction is almost carried out in the carbon fiber interior (such as the fiber axis). There are only some contact points between the fiber layers. Phonon or electronic vibration is difficult to carry out in these connection contact points, so heat conduction is very small. Even if it can, it will take a long journey, so heat transfer is also very little. The above description can be shown in Figure 6. The heat conduction route is relatively zigzag, that is, most of the carbon fibers are perpendicular to the heat flow conduction direction, and there are fewer carbon fibers parallel to or deviating from the heat flow conduction direction. Even if 


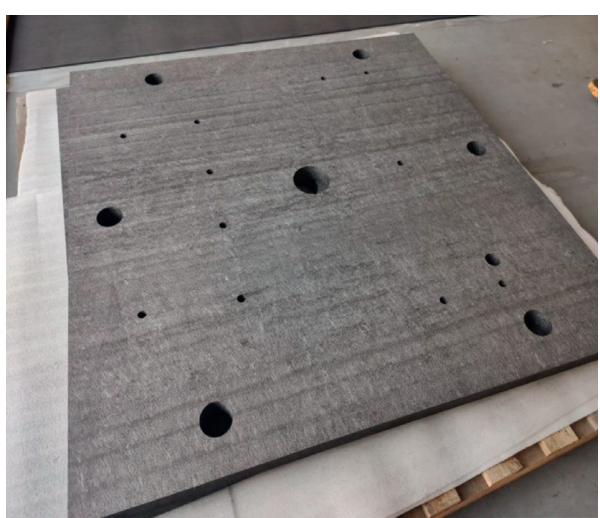

(a)

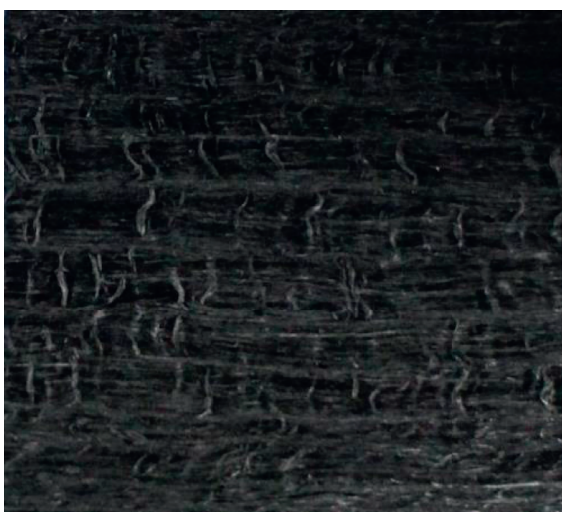

(c)

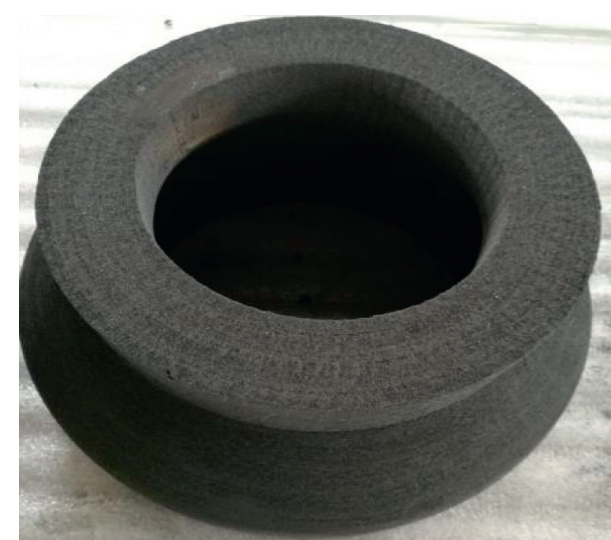

(b)

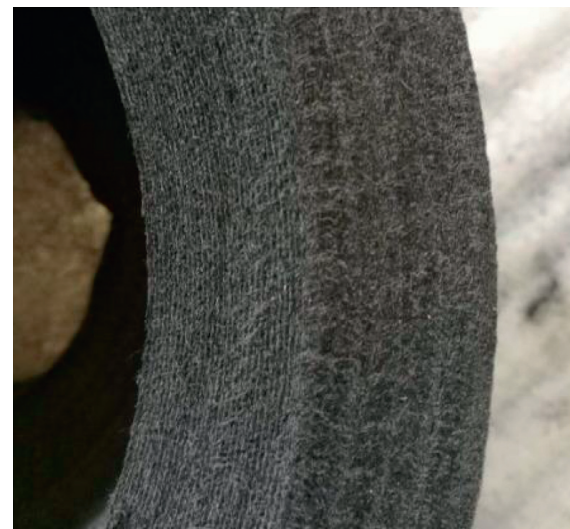

(d)

FiguRE 4: Carbon/carbon fiber composites: (a) plate material, (b) shaped material, (c) layer structure of the plate material, and (d) layer structure of the shaped material.

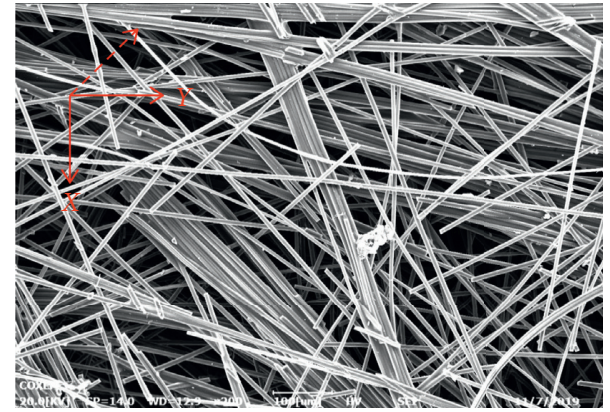

(a)

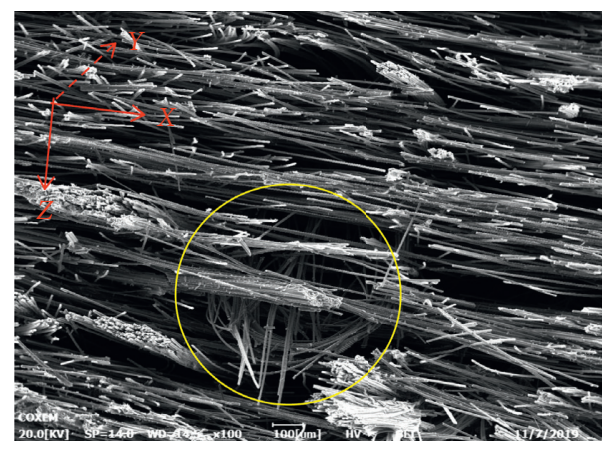

(c)

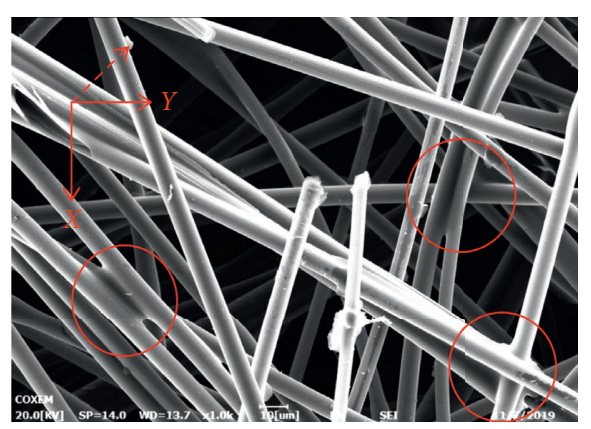

(b)

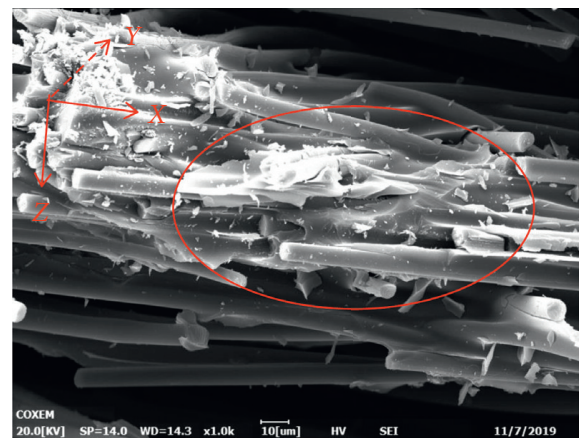

(d)

FiguRE 5: SEM images of carbon/carbon fiber composites: (a) and (b) inner surface (parallel to the laminate); (c) and (d) section (vertical to the laminate). 


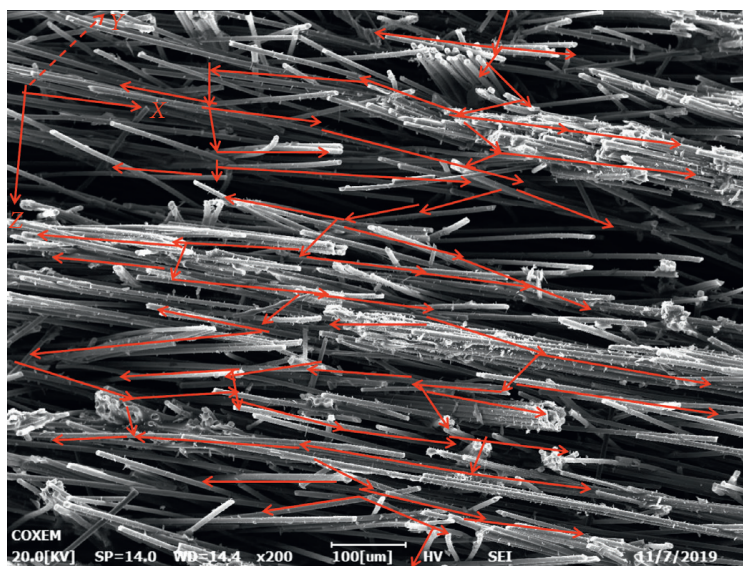

Figure 6: Heat transfer model in the carbon/carbon fiber composite.

there are carbon fibers parallel to the heat flow conduction direction, their carbon fibers cannot pass through both sides of the composite material, so the heat transmitted by heat conduction is less.

From the above analysis, it can be seen that the heat transferred by heat convection and heat conduction is very little, so the main way of heat transfer is heat radiation. Under the condition of high-temperature inertia or vacuum, heat transfer is mainly heat radiation, and there is indirect radiation in the process of heat radiation. The indirect radiation can radiate to the direction of heat transfer, further offsetting part of heat transfer. Therefore, the lightweight carbon/carbon fiber composite with this structure has better heat preservation effect. This kind of carbon/carbon fiber composite can play a better role in heat preservation, ensure the stability of the thermal field in the high-temperature furnace, and make the crystal growth stable.

Figure 7 shows the thermal conductivity diagram of the carbon/carbon fiber composite at room temperature and above $1200^{\circ} \mathrm{C}$. In the high-temperature environment, with the increasing temperature, the thermal radiation of the carbon/ carbon fiber composite increases, so the thermal conductivity also increases from $0.076 \mathrm{~W} /(\mathrm{mK})\left(25^{\circ} \mathrm{C}\right)$ to $0.170 \mathrm{~W} /(\mathrm{mK})$ $\left(1200^{\circ} \mathrm{C}\right)$. In the high-temperature environment above $1200^{\circ} \mathrm{C}$, the main way of heat transfer is heat radiation, so the purpose of heat insulation is to suppress heat radiation. In the case of constant $Z$-dimension, increasing the number of $X-Y$ fiber layers by selecting fibers with small fiber diameter can reduce the internal radiation heat of the material. At present, the diameter of the carbon fiber is gradually reduced from $7 \mu \mathrm{m}$ (T300) to $5 \mu \mathrm{m}$ (T700), which will increase the heat insulation effect of the carbon fiber felt $[35,36]$.

\subsection{Electrical Property Analysis of Carbon/Carbon Fiber} Composites. The higher the conductivity of the carbon/ carbon fiber composite, the better the conductivity of the carbon/carbon fiber material. The conductivity of the carbon/carbon fiber composite is related to the final degree of graphitization of the carbon/carbon fiber material. In general, the higher the degree of graphitization, the better the

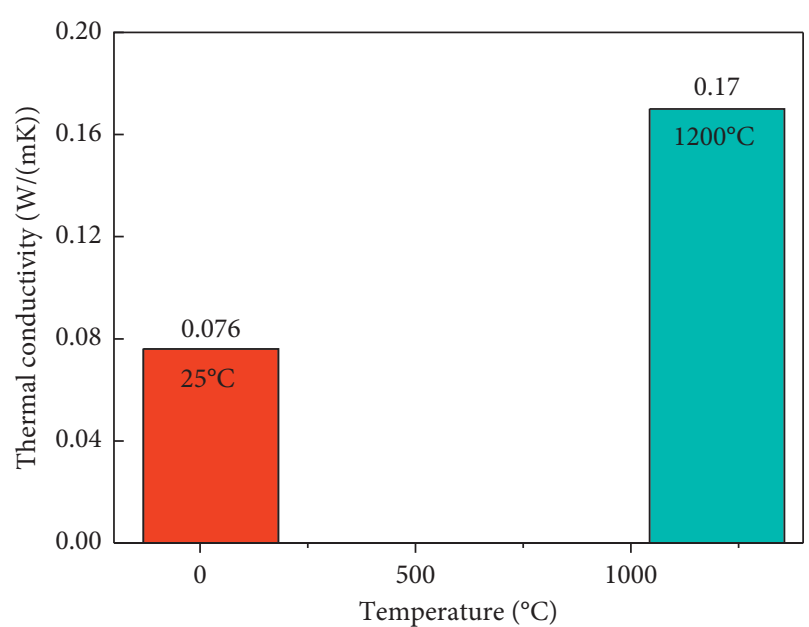

FIGURE 7: Thermal conductivity diagram of the carbon/carbon fiber composite.

oxidation resistance of the carbon/carbon fiber material. Therefore, it is necessary to test the volume conductivity of the carbon/carbon fiber material. According to the resistance of the carbon/carbon fiber composite measured by the four-probe method, the conductivity of the carbon/carbon fiber composite can be calculated. The resistance test curves are shown in Figures 8 and 9. The electrical conductivity data table of the carbon/carbon fiber composite is shown in Tables 1 and 2. Figure 8 shows the relationship between voltage drop at both ends of the probe and current (perpendicular to the plane direction). Figure 9 shows the relationship between voltage drop at both ends of the probe and current (plane direction). Table 1 shows the electrical conductivity data of the carbon/carbon fiber composite (perpendicular to the plane direction). Table 2 shows the electrical conductivity data of the carbon/carbon fiber composite (plane direction).

It can be seen from the chart that the electrical conductivity perpendicular to the plane direction is $182.8 \mathrm{~S} / \mathrm{m}$, far less than $1452.4 \mathrm{~S} / \mathrm{m}$ in the plane direction, which is determined by the three-dimensional structure of carbon/ carbon fiber composite. It can be seen from the SEM images that the carbon fibers are almost all arranged along the $X-Y$ plane, and there are few fibers in the $Z$ direction. Carbon fibers have a certain length diameter ratio, and the electrons are easy to propagate along the fiber direction, so the electrons propagate in the $X-Y$ plane, that is, the electrical conductivity is high. In addition, in the same transmission distance, the contact interface between the fiber and the fiber in the $X-Y$ plane is less, and the interface resistance is small, so the electrical conductivity is high. In the $Z$ direction, the interface is more, and the interface resistance is large, so the electrical conductivity is low. Considering the interface resistance, the conductivity in the $X-Y$ plane direction is also higher than that in the $Z$ direction.

3.4. Compressive Strength and Compression Mechanism Analysis of Carbon/Carbon Fiber Composites. In the hightemperature furnace, the lightweight carbon/carbon fiber 


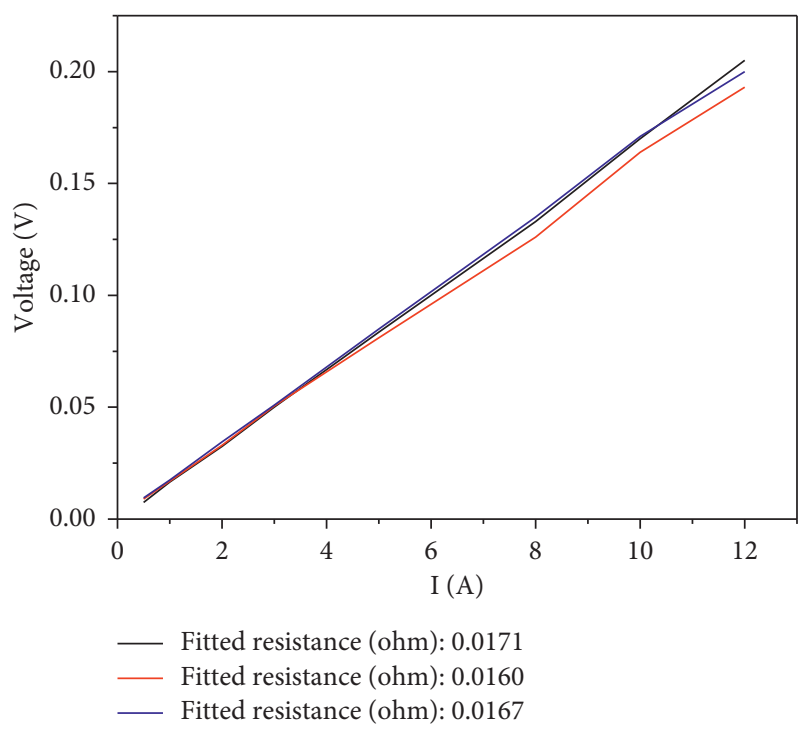

Figure 8: Relationship between voltage drop at both ends of the probe and current (perpendicular to the plane direction).

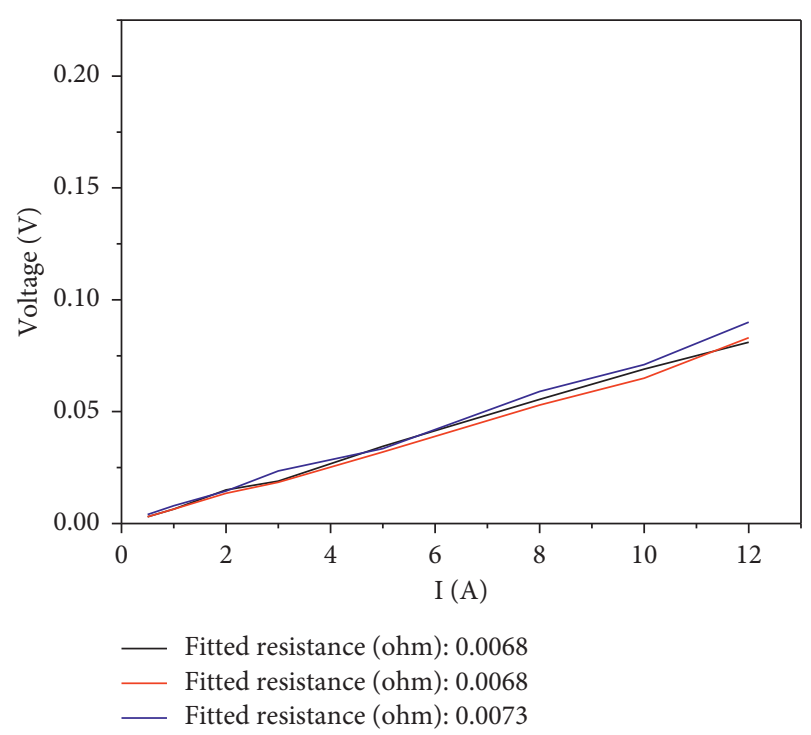

Figure 9: Relationship between voltage drop at both ends of the probe and current (plane direction).

TABLE 1: Electrical conductivity data of the carbon/carbon fiber composite (perpendicular to the plane direction).

\begin{tabular}{lcccc}
\hline & $L(\mathrm{~m})$ & $S\left(\mathrm{~m}^{2}\right)$ & $R(\Omega)$ & $\sigma=L / R S(\mathrm{~S} / \mathrm{m})$ \\
\hline 1 & 0.05 & 0.004947 & 0.0171 & 177.3 \\
2 & 0.05 & 0.004947 & 0.0160 & 189.5 \\
3 & 0.05 & 0.004947 & 0.0167 & 181.6 \\
Average & & & & 182.8 \\
\hline
\end{tabular}

composite has many advantages with certain strength. (1) It is conducive to the installation and replacement of the lightweight carbon/carbon fiber composite. (2) It is conducive to the stability of the shape of the heat field material,
TABLE 2: Electrical conductivity data of the carbon/carbon fiber composite (plane direction).

\begin{tabular}{lcccc}
\hline & $L(\mathrm{~m})$ & $S\left(\mathrm{~m}^{2}\right)$ & $R(\Omega)$ & $\sigma(\mathrm{S} / \mathrm{m})$ \\
\hline 1 & 0.05 & 0.004947 & 0.0068 & 1486.3 \\
2 & 0.05 & 0.004947 & 0.0068 & 1486.3 \\
3 & 0.05 & 0.004947 & 0.0073 & 1384.5 \\
Average & & & & 1452.4 \\
\hline
\end{tabular}

so as to ensure that the energy in the heat field can be distributed according to the simulated and designed space geometry under high-temperature conditions. The uniform distribution of heat field energy is beneficial to the growth of the crystal. (3) Certain mechanical strength can ensure that the heat field material can withstand the scour of various high-temperature gases and increase the service life of the heat field material. Figure 10 shows the compression failure process diagrams of carbon/carbon fiber composites. Figure 11 shows the compressive strength diagrams of carbon/carbon fiber composites. Lightweight carbon/carbon fiber composite is a lightweight foamed material composed of carbon fiber and bonded carbon. Its density is about $0.16 \mathrm{~g} / \mathrm{cm}^{3}$, far below the density of the high-density carbon/carbon fiber material $\left(1.8 \mathrm{~g} / \mathrm{cm}^{3}\right)$. Therefore, the compressive strength will change due to the destruction of the carbon skeleton or carbon fiber skeleton and compression deformation during compression. From Figure 11(a), it can be seen that the compressive strength of the carbon/carbon fiber composite increases gradually with the increase of compression ratio. After $0.2 \mathrm{MPa}$, the increasing trend slows down, but the compressive strength is still a gradual increasing process. In the process of material compression before $0.2 \mathrm{MPa}$, due to the gap between carbon fiber layers in carbon/carbon fiber composites, the pores are gradually compressed, and the material strength is gradually increased. When the pressure is $0.2 \mathrm{MPa}$, the carbon skeleton of the bonded carbon fiber laminated materials cannot bear the pressure and is damaged. After the pressure $0.2 \mathrm{MPa}$, the gap of the carbon/carbon fiber composite continues to be compressed, and the remaining part of the carbon skeleton is also destroyed, the strength gradually increases, but the increasing trend becomes slower. In Figures 10(a) and 10(b), it can be found that, during compression, the structure of the carbon fiber felt is not damaged (which can be verified by the repeated tests below), but the distance between the carbon fiber felt layer and the layer becomes smaller, so there is no sign of damage on the overall structure of the carbon fiber block from the macrostructure.

In Figure 11(b), the compressive strength of the carbon/ carbon fiber composites in the $X$ direction (or $Y$ direction) is between $1.31 \mathrm{MPa}$ and $1.65 \mathrm{MPa}$, which is much higher than the $Z$-direction compressive strength $(0.2 \mathrm{MPa})$. In Figure 11(b), it can be found that there is a yield point in the compression curve in the $Z$ direction, and the compressive strength increases gradually before the yield point. After the yield point, the compressive strength curve shows a wave shape. The change trend of the compressive strength in the $X$ (or $Y$ ) direction is different from that in the $Z$ direction, 


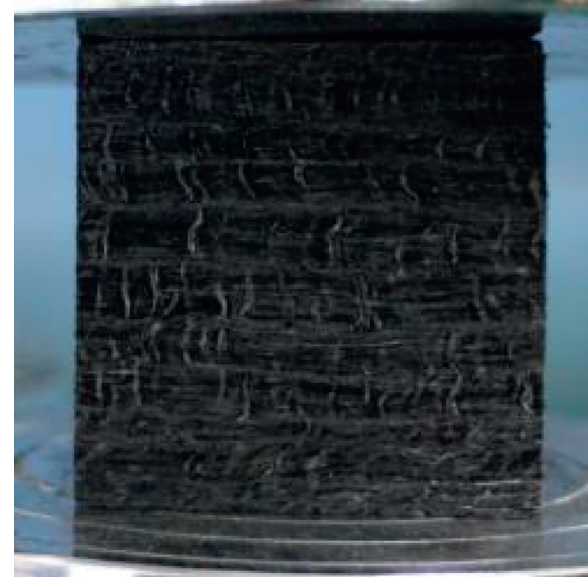

(a)

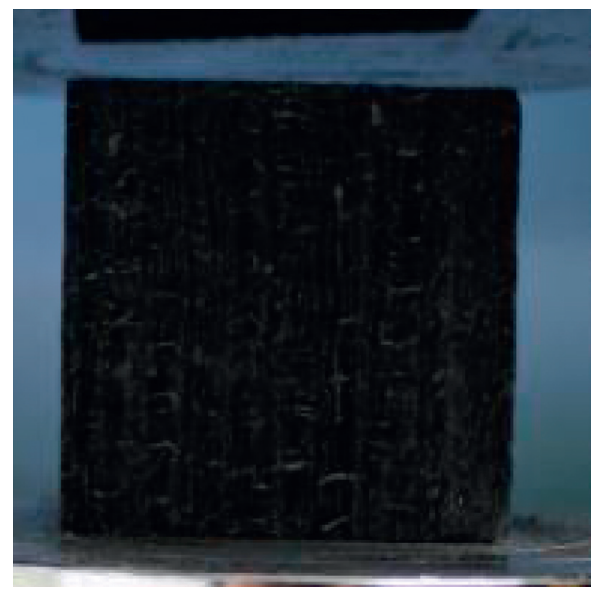

(c)

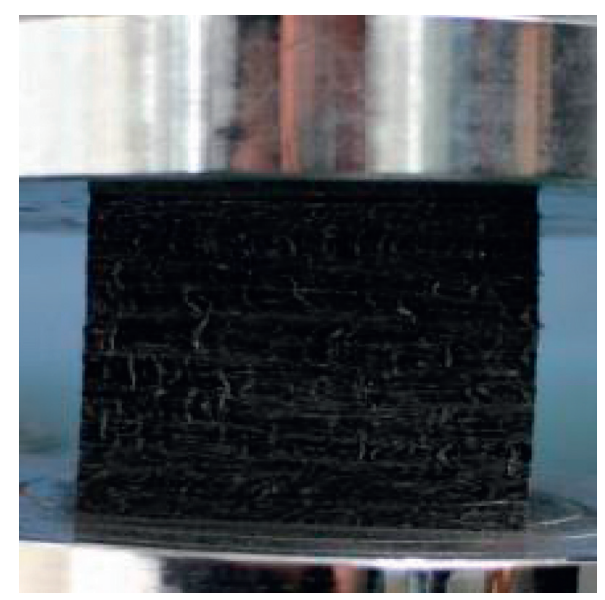

(b)

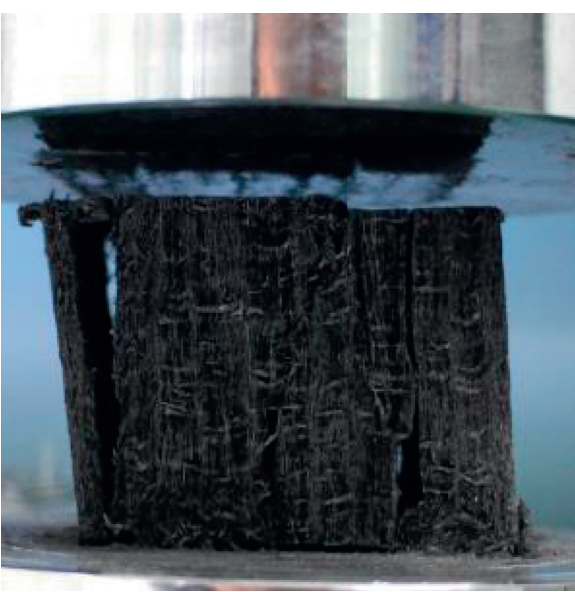

(d)

FIGURE 10: Compression failure process diagrams of carbon/carbon fiber composites: (a), (b) front compression ( $Z$ direction); (c), (d) side compression ( $X$ direction or $Y$ direction).

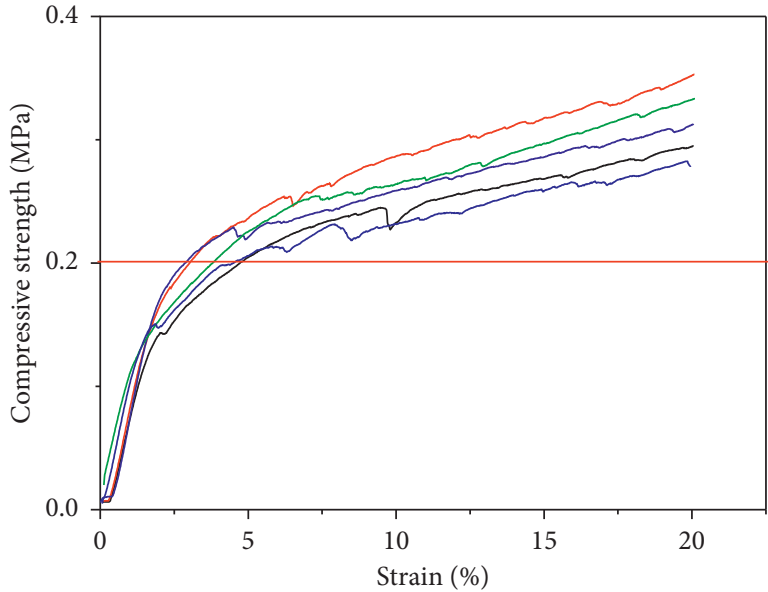

(a)

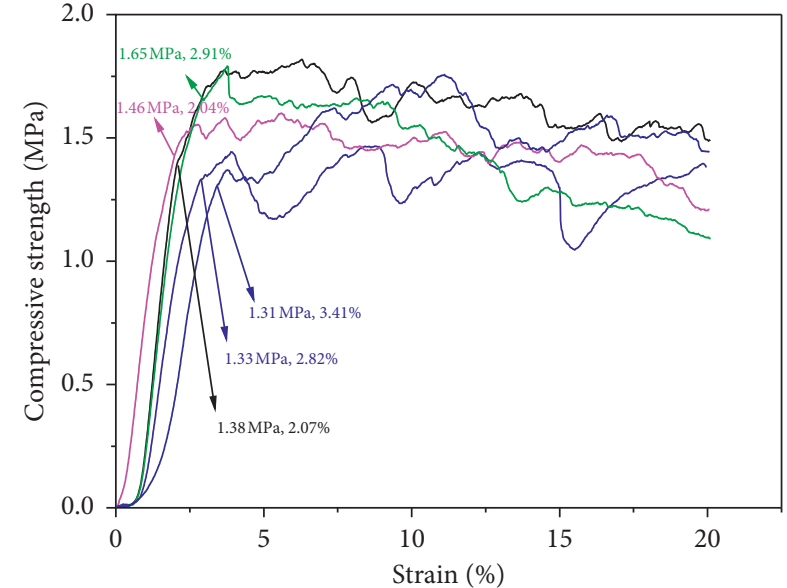

(b)

FIgURE 11: Compressive strength diagrams of carbon/carbon fiber composites: (a) front compression ( $Z$ direction); (b) side compression ( $X$ direction or $Y$ direction). 
which is determined by the inhomogeneous structure of the carbon/carbon fiber composite. Figure 12 shows the compression failure mechanism diagrams of carbon/carbon fiber composites. In the process of compression in the $Z$ direction, carbon/carbon fiber composites can compress in the $Z$ direction by compressing the gap. The carbon skeleton binds the carbon fiber felt together, so if the material is compressed in the $X$ direction (or $Y$ direction), the fibers in other directions in the $X-Y$ plane will block the compression (as shown in Figure 12(a)), so the compressive strength can reach above $1.31 \mathrm{MPa}$. When the pressure is large enough, the bonded carbon structure in the carbon/carbon fiber composite will be destroyed, and the carbon fiber felt will expand laterally (Figure 12(b)), and the carbon fiber felt will peel off and expand between layers. Under the action of pressure, the phenomenon of peeling between carbon fiber layers occurs continuously, so the wave shape change of pressure appears. The delamination expansion between carbon fiber layers can be verified by Figure 10(d). In Figure 10(d), obvious delamination occurs between layers of the carbon/carbon fiber composite.

The side compression ( $X$ or $Y$ direction) caused peeling damage to the material, and the surface compression $(Z$ direction) did not cause great macroscopic damage to the macroscopic structure of the carbon/carbon fiber material. In order to further verify the damage mechanism of the $Z$ direction compression on the carbon/carbon fiber material, the carbon/carbon fiber was repeatedly compressed for 3 times. Figure 13 shows the repeated front compression failure process diagrams of carbon/carbon fiber composites. Figure 14 shows the repeated front compressive strength diagrams of carbon/carbon fiber composites. As can be seen from Figure 13, after the carbon/carbon fiber material has been compressed for the first time (Figure 13(a)), the material can be restored to its original size (Figure 13(b)). After the composite (Figure 13(b)) is compressed, it can also be restored to its original size (Figure 13(c)). The dimensions of materials (Figures 13(a)-13(c)) did not change significantly, indicating that the carbon fiber felt structure of the carbon/ carbon fiber composite did not undergo destructive structural changes so that the composite material could quickly restore the original macroscopic morphology. As can be seen from Figure 14, when the material is subjected to the first compression, there is a yield point at a position of $0.2 \mathrm{MPa}$, which has been analyzed from the above that the carbon bonded structure of the bonded carbon fiber felt body is broken. After the second compression, the yield point of the material disappeared, confirming the destruction of the carbon bonded structure. The material after the third compression also has no yield point, which is similar to the second time compression curve, with only minor changes, possibly due to the destruction of the microcarbon bonded structure.

Looking at the curves in Figure 14, it can be found that, after $20 \%$ compression deformation, the three curves of the compressive strength of the material all reach $0.3 \mathrm{MPa}$, and the differences are not large. At the time after 20\% compression deformation, the material reaches certain compression density, and the broken carbon particles play a role of skeleton support so that the material has high strength. This kind of support strength is recoverable strength. It may take several times to destroy the material, which is a better phenomenon. This ensures that the material can withstand multiple compression shocks during installation and use. Especially in high-temperature equipment, carbon/carbon fiber composite needs to withstand the impact of hightemperature, high-speed airflow. At this time, even if the carbon skeleton is destroyed, the compression recovery of the carbon/carbon fiber composite can ensure the use performance of the material.

\subsection{Bending Property Analysis of Carbon/Carbon Fiber} Composites. When the carbon/carbon fiber composite is subjected to the bending force, the bending strength changes. The reason for the change in the bending strength is also determined by the structure of the carbon/carbon fiber composite. That is, the bending strength of the carbon/ carbon fiber composite is also determined by the bonding carbon and carbon fiber felt structure. Figure 15 shows the bending failure process diagrams of carbon/carbon fiber composites. Figure 16 shows the bending strength diagrams of carbon/carbon fiber composites. It can be seen from Figure 16(a) that the bending yield strength of the carbon/ carbon fiber composite ( $Z$ direction) is $0.24 \mathrm{MPa}-0.39 \mathrm{MPa}$. After the carbon/carbon fiber composite bends and yields, the strength gradually decreases. It can be seen from Figure 15(a) that, as the bending deformation increases, the carbon/carbon fiber composites show delamination in the middle position in Figure 15(b), and then, even a very large slip occurs between the layers (see both ends of the sample in Figure 15(c)). This phenomenon is due to the fact that, during the bending process, the bending deformation of the underlying felt of the carbon fiber is different from the bending deformation of the upper felt body. And after reaching certain bending strength, the carbon skeleton structure in the carbon/carbon fiber composite is broken, and the yielding phenomenon will occur. After the carbon skeleton is broken, the adhesion force between the carbon fiber felt layer and the layer is reduced. When the compression continues, the difference between the bending deformation of the upper and lower felt bodies continues to increase, and delamination and slippage of the felt body will occur. Especially in the middle position of the carbon/ carbon fiber composite, the amount of deformation of the upper and lower bends is large, and delamination and slippage are also the most serious shown in Figure 15(c).

In Figure 16(b), the side bending strength of the carbon/ carbon fiber composite is higher than $1.1 \mathrm{MPa}$, which is much higher than the front bending strength $(0.24 \mathrm{MPa})$ in Figure 16(a). This is determined by the three-dimensional $X$ $Y-Z$ structure of the carbon/carbon fiber composite. In the case of side bending, the amount of bending deformation of the lower part of the carbon/carbon fiber composite is also different from that of the upper part. At this time, the carbon/carbon fiber composite cannot achieve large deformation by slippage between carbon fiber layers. The lower part of the material is subjected to the tensile force from both 


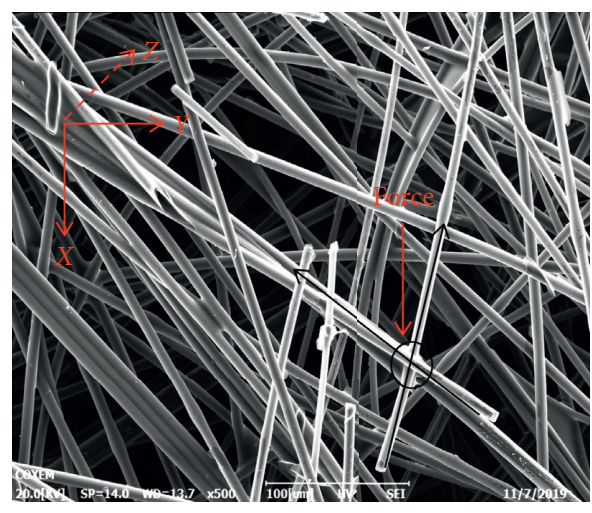

(a)

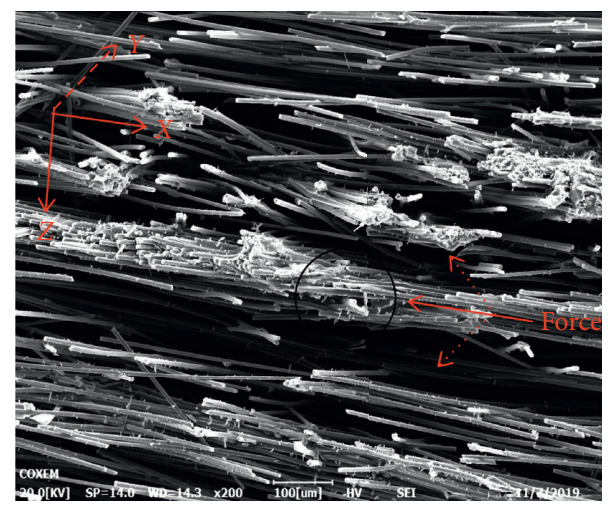

(b)

Figure 12: Compression failure mechanism diagrams of carbon/carbon fiber composites: (a) inner surface (parallel to the laminate); (b) section (vertical to the laminate).

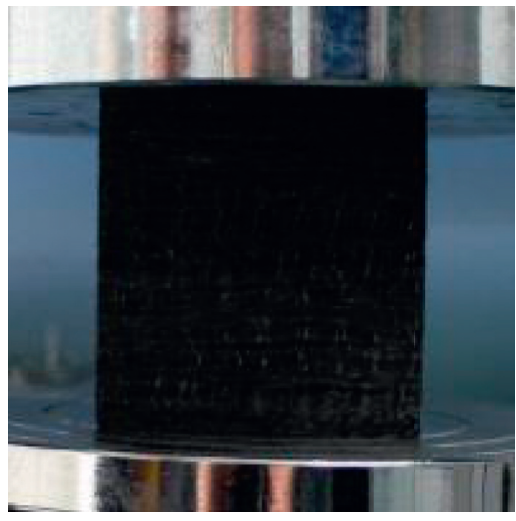

(a)

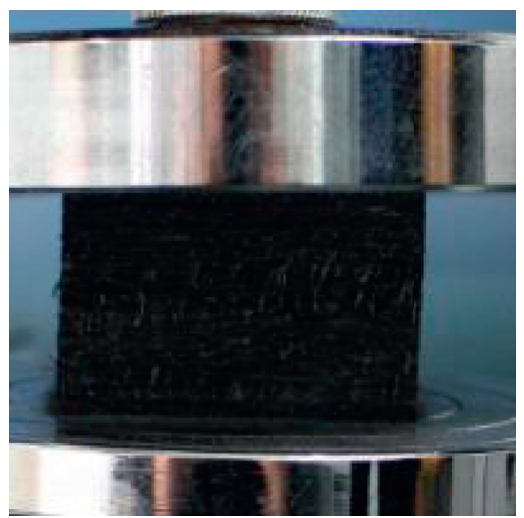

(d)

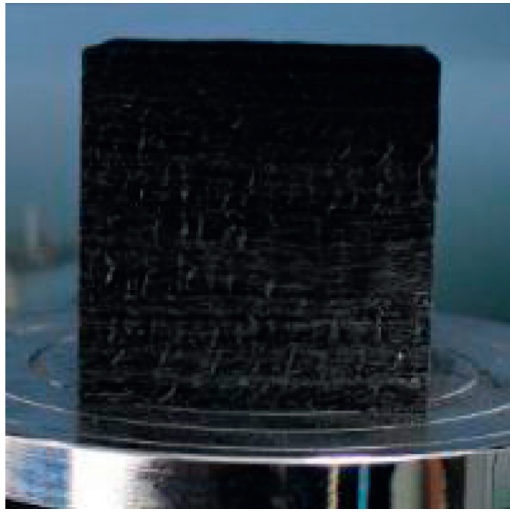

(b)

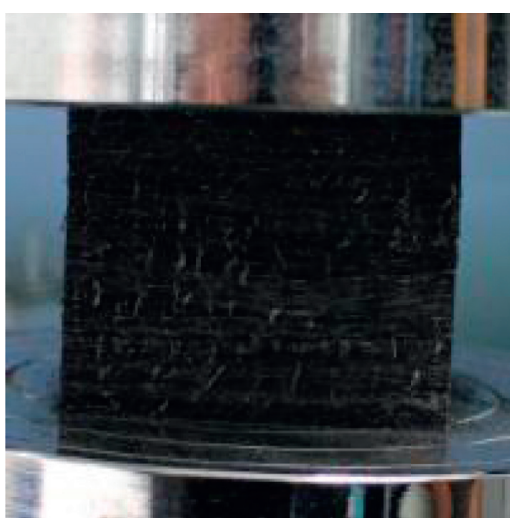

(e)

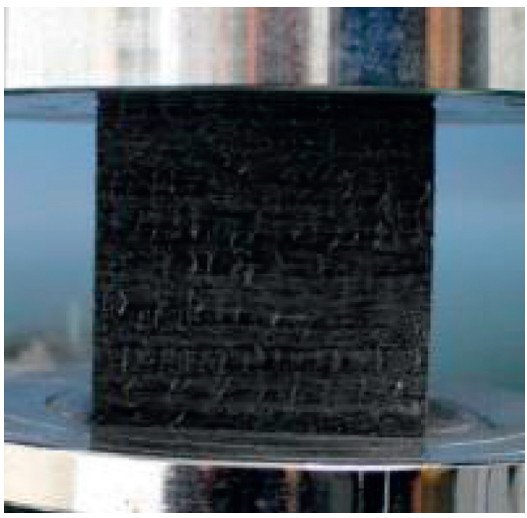

(c)

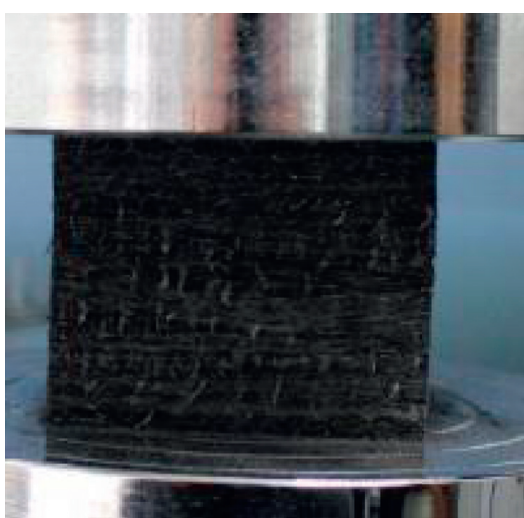

(f)

FIgURE 13: Repeated front compression failure process diagrams of carbon/carbon fiber composites.

ends. After the carbon structure of the carbon/carbon fiber composite material is broken, the large deformation can be achieved only by pulling of the carbon fiber. The force of the destruction of the carbon structure plus the fiber pulling force is obviously higher than the slip force between the layers (the force of carbon structure damage), so the side bending force of the carbon/carbon fiber composite is greater than the front bending force. In Figures 15(d)-15(f), it can be seen that the side bending of the carbon/carbon fiber composite is a destructive bend. As the bending deformation increases, the fibers in the lower-middle of the sample are gradually pulled off with a small gap 


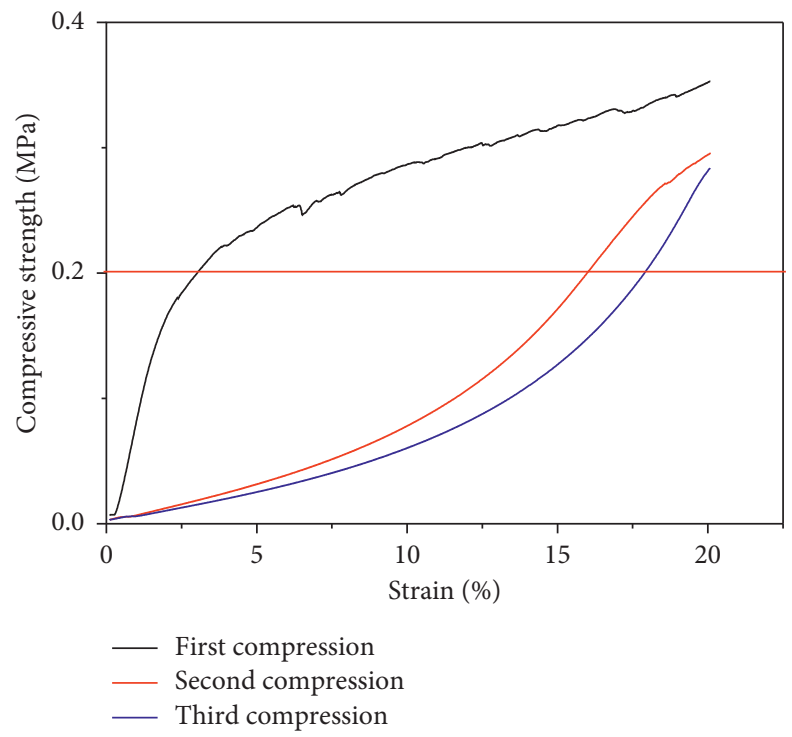

FIGURE 14: Repeated front compressive strength diagrams of carbon/carbon fiber composites.

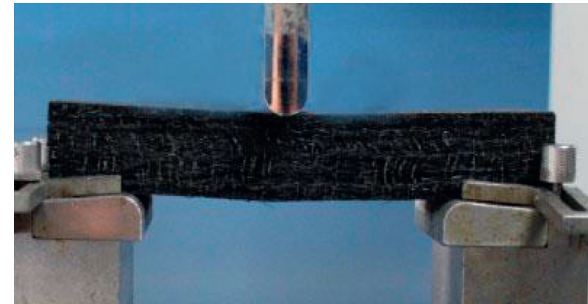

(a)

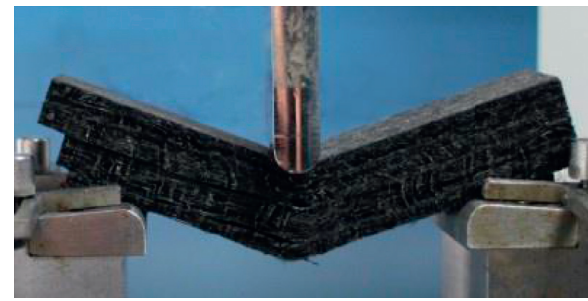

(c)

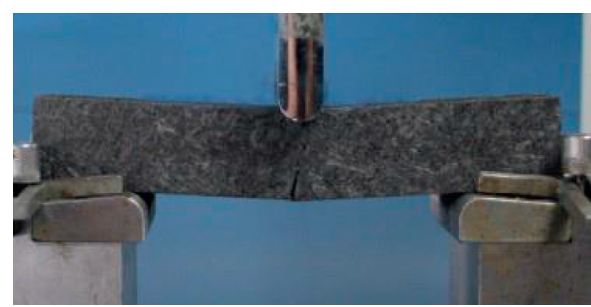

(e)

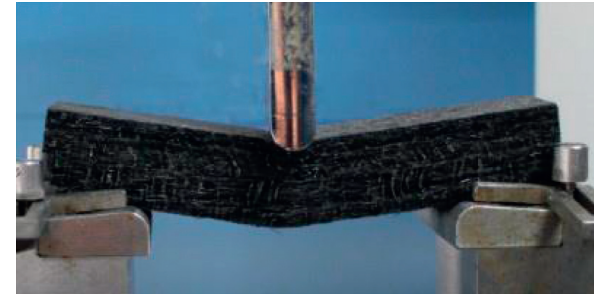

(b)

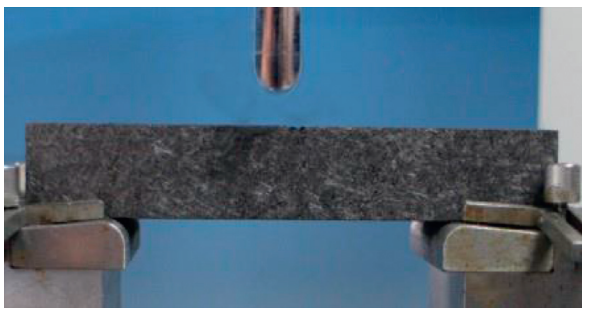

(d)

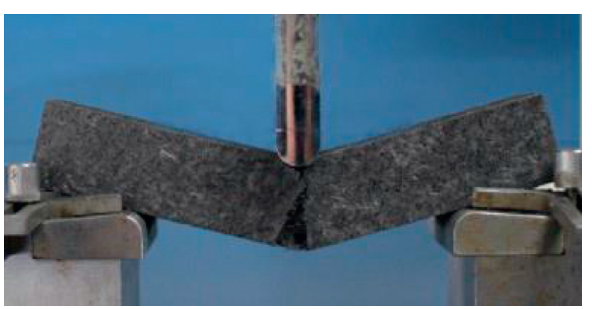

(f)

FIGURE 15: Bending failure process diagrams of carbon/carbon fiber composites: (a), (b), and (c) front bending ( $Z$ direction); (d), (e), and (f) side bending ( $X$ direction or $Y$ direction).

(Figure 15(e)) followed by a large gap (Figure 15(f)), and the material will eventually break.

At the same time, comparing the curves of Figures 16(a) and 16(b), it can be seen that, in Figure 16(a), the bending deformation curve is very smooth, and the bending deformation curve of Figure 16(b) rises like a wave. During the side bending process, part of the fibers in the lower-middle part of the sample will cause partial force to disappear when 


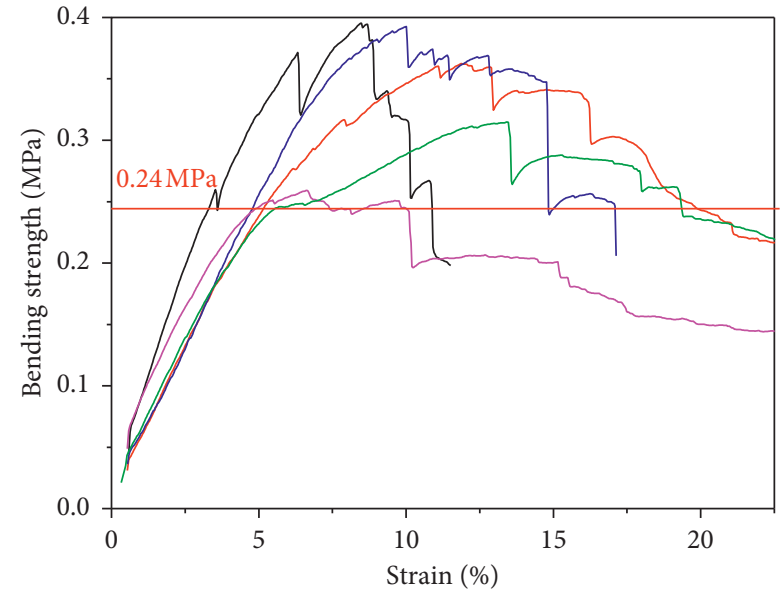

(a)

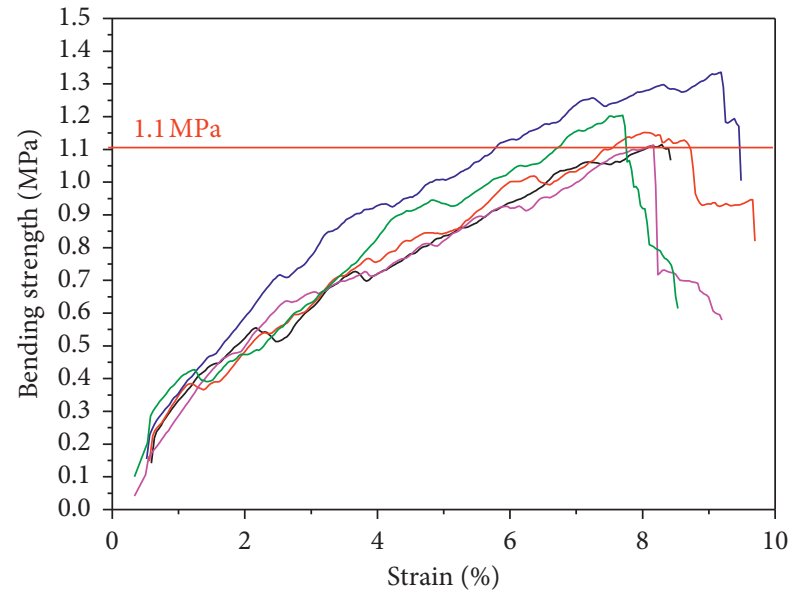

(b)

FIGURE 16: Bending strength diagrams of carbon/carbon fiber composites: (a) front bending ( $Z$ direction); (b) side bending ( $X$ direction or $Y$ direction).

it is completely pulled off, but another part of the fibers is resisting the bending and pulling force, so there is a situation of rising waves.

\section{Conclusions}

In this paper, lightweight carbon/carbon fiber composites were successfully prepared by long carbon fiber airflow netting-needle punching forming felt-resin impregnationmolding curing-high-temperature carbonization and graphitization, and the microstructure, thermal conductivity, and electrical conductivity of the composites were obtained. The mechanical properties have also been studied, and the following conclusions can be drawn:

(1) A lightweight carbon/carbon fiber composite with the three-dimensional $X-Y-Z$ structure was successfully prepared, and the fiber arrangement in the composite showed anisotropy.

(2) The anisotropic structure of the lightweight carbon/ carbon fiber composite makes the lightweight carbon/carbon fiber composite have lower thermal conductivity and better thermal insulation performance.

(3) The anisotropic structure of the lightweight carbon/ carbon fiber composite makes the composite have the electrical conductivity in-plane $(1452.4 \mathrm{~S} / \mathrm{m})$, much higher than the electrical conductivity in the direction perpendicular to the plane direction $(182.8 \mathrm{~S} / \mathrm{m})$.

(4) The anisotropic structure of the lightweight carbon/ carbon fiber composite makes the material have the side compressive strength $(>1.31 \mathrm{MPa})$ and the side bending strength $(>1.1 \mathrm{MPa})$, much higher than the front compressive strength $(>0.2 \mathrm{MPa})$ and the front bending strength $(>0.24 \mathrm{MPa})$. In addition, the lightweight carbon/carbon fiber composite has reversible front compression characteristics.
The preparation of the lightweight carbon/carbon fiber composite will provide a reference for its application in crystal growth furnaces and other high-temperature insulation environments.

\section{Data Availability}

The data used to support the findings of this study are available from the corresponding author upon request.

\section{Conflicts of Interest}

The authors declare no conflicts of interest.

\section{Acknowledgments}

This work was supported by the project funded by the China Postdoctoral Science Foundation (2017M611757), Shanghai Science and Technology Talent Planning Project (19QB1402200), the Capacity Improvement Project for Municipal Universities in Shanghai by Shanghai Science and Technology Commission (19040501800), the Special Fund of the National Natural Science Foundation of China (51573201, 51871146, 51803119, and 51771108), Chenguang Program supported by the Shanghai Education Development Foundation and Shanghai Municipal Education Commission (18CG56), and the Innovation Program of Shanghai Municipal Education Commission (2019-01-0700-10-E00053).

\section{References}

[1] C. G. Li and G. J. Xian, "Experimental investigation of the microstructures and tensile properties of polyacrylonitrilebased carbon fibers exposed to elevated temperatures in air," Journal of Engineered Fibers and Fabrics, vol. 14, 2019.

[2] W. Liu, Y. Gao, X. Y. Liu, Y. P. Qiu, and F. J. Xu, "Tensile and interfacial properties of dry-jet wet-spun and wet-spun polyacrylonitrile-based carbon fibers at cryogenic condition," Journal of Engineered Fibers and Fabrics, vol. 14, 2019. 
[3] A. S. Ahmed, Z. Chlup, I. Dlouhy, R. D. Rawlings, and A. R. Boccaccini, "Mechanical properties of low-density SiCcoated carbon-bonded carbon fiber composites," International Journal of Applied Ceramic Technology, vol. 9, no. 2, pp. 401-412, 2012.

[4] A. S. Ahmed, R. D. Rawlings, S. D. Ellacott, and A. R. Boccaccini, "Oxidation and thermal degradation resistance of silicon carbide coated low density carbon-carbon composite," Advances in Applied Ceramics, vol. 112, no. 1, pp. 23-32, 2013.

[5] Q. Li, J. Q. Liu, A. Y. Bai et al., "Preparation of a nitrogendoped reduced graphene oxide-modified graphite felt electrode for $\mathrm{VO} 2+/ \mathrm{VO} 2+$ reaction by freeze-drying and pyrolysis method," Journal of Chemistry, vol. 2019, Article ID 8958946, 9 pages, 2019.

[6] Y. Li, X. J. Meng, Y. Jia, S. A. Chen, M. Mei, and G. D. Li, "Properties of $\mathrm{C} / \mathrm{C}-\mathrm{ZrC}$ composites prepared by precursor infiltration and pyrolysis with a meltable precursor," Materials Research Express, vol. 6, p. 085632, 2019.

[7] W. Zhou, P.-F. Zhang, H.-F. Yin, and Y.-J. Shang, "Flexural damage behavior of carbon fiber three-dimensional braided composites using acoustic emission and micro-CT," Materials Research Express, vol. 6, no. 11, p. 115601, 2019.

[8] T. B. Cheng, R. B. Zhang, Y. M. Pei, R. J. He, D. N. Fang, and Y. Z. Yang, "Flexural properties of carbon-carbon composites at temperatures up to 2600 degrees C," Materials Research Express, vol. 6, p. 085629, 2019.

[9] W. Zhou, K. N. Han, R. Qin, and Y. J. Zhang, "Investigation of mechanical behavior and damage of three-dimensional braided carbon fiber composites," Materials Research Express, vol. 6, p. 085624, 2019.

[10] C. Wang, X. Jin, H. Cheng, C. Hong, and X. Zhang, "Organic aerogel-impregnated low-density carbon/carbon composites: preparation, properties and response under simulated atmospheric re-entry conditions," Materials \& Design, vol. 131, pp. 177-185, 2017.

[11] B. K. Bessire, S. A. Lahankar, and T. K. Minton, "Pyrolysis of phenolic impregnated carbon ablator (PICA)," ACS Applied Materials \& Interfaces, vol. 7, no. 3, pp. 1383-1395, 2015.

[12] M. Natali, I. Puri, J. M. Kenny, L. Torre, and M. Rallini, "Microstructure and ablation behavior of an affordable and reliable nanostructured Phenolic Impregnated Carbon Ablator (PICA)," Polymer Degradation and Stability, vol. 141, pp. 84-96, 2017.

[13] B. K. Bessire and T. K. Minton, "Decomposition of phenolic impregnated carbon ablator (PICA) as a function of temperature and heating rate," ACS Applied Materials \& Interfaces, vol. 9, no. 25, pp. 21422-21437, 2017.

[14] H.-W. Wong, J. Peck, J. Assif, F. Panerai, J. Lachaud, and N. N. Mansour, "Detailed analysis of species production from the pyrolysis of the phenolic impregnated carbon ablator," Journal of Analytical and Applied Pyrolysis, vol. 122, pp. 258-267, 2016.

[15] M. Rivier, J. Lachaud, and P. M. Congedo, "Ablative thermal protection system under uncertainties including pyrolysis gas composition," Aerospace Science and Technology, vol. 84, pp. 1059-1069, 2019.

[16] H. Cheng, C. Hong, X. Zhang, and H. Xue, "Lightweight carbon-bonded carbon fiber composites with quasi-layered and network structure," Materials \& Design, vol. 86, pp. 156-159, 2015.

[17] C. Liu, J. Han, X. Zhang, C. Hong, and S. Du, "Lightweight carbon-bonded carbon fiber composites prepared by pressure filtration technique," Carbon, vol. 59, pp. 551-554, 2013.
[18] H. Cheng, H. Xue, C. Hong, and X. Zhang, "Preparation, mechanical, thermal and ablative properties of lightweight needled carbon fibre felt/phenolic resin aerogel composite with a bird's nest structure," Composites Science and Technology, vol. 140, pp. 63-72, 2017.

[19] B. Tang, Y. Wang, L. Hu et al., "Preparation and properties of lightweight carbon/carbon fiber composite thermal field insulation materials for high-temperature furnace," Journal of Engineered Fibers and Fabrics, vol. 14, 2019.

[20] B. Li, J. Liao, Z. Chen et al., "High-performance Cf/SiC composites with a novel needle-punched carbon fiber fabric fabricated by PIP process," Materials Research Express, vol. 6, no. 11, p. 115622, 2019.

[21] H. C. Shao, G. W. Liu, G. J. Qiao et al., "Preparation and protective surface coatings for low density C/C composite for harden insulation," Materials Research Innovations, vol. 17, no. 4, pp. 228-237, 2013.

[22] A. S. Ahmed, R. D. Rawlings, S. D. Ellacott, and A. R. Boccaccini, "Microstructural and compositional characterisation of the pyrocarbon interlayer in $\mathrm{SiC}$ coated low density carbon/carbon composites," Journal of the European Ceramic Society, vol. 31, no. 1-2, pp. 189-197, 2011.

[23] J. J. Shi, Z. B. Zhang, Z. H. Feng, D. H. Zhang, Y. Wang, and C. $\mathrm{H}$. $\mathrm{Xu}$, "Modification of oxidation resistance for low density carbon-bonded carbon fiber (CBCF) composite," Journal of Inorganic Materials, vol. 33, pp. 728-734, 2018.

[24] L. Xu, W. Yang, Z. Fan et al., "Fabrication of low-density carbon-bonded carbon fiber composites with an Hf-based coating for high temperature applications," RSC Advances, vol. 8, no. 34, pp. 19171-19180, 2018.

[25] F. Smeacetto, M. Ferraris, M. Salvo et al., "Protective coatings for carbon bonded carbon fibre composites," Ceramics International, vol. 34, no. 5, pp. 1297-1301, 2008.

[26] J. Li, J. Sha, J. Dai et al., "Fabrication and characterization of carbon-bonded carbon fiber composites with in-situ grown SiC nanowires," Carbon, vol. 118, pp. 148-155, 2017.

[27] M. Niu, H. Wang, L. Su, D. Zhang, and J. Shi, "Fabrication and properties of lightweight SiOC modified carbon-bonded carbon fiber composites," Ceramics International, vol. 42, no. 9, pp. 10614-10618, 2016.

[28] M. Niu, H. Wang, J. Wen, M. Ma, and X. Fan, "Preparation and anti-oxidation properties of $\mathrm{Si}(\mathrm{O}) \mathrm{C}$ coated carbonbonded carbon fibre composites," RSC Advances, vol. 5, no. 65, pp. 52347-52354, 2015.

[29] M. A. Shayed, H. Hund, R. D. Hund, and C. Cherif, "Thermal and oxidation protection of carbon fiber by continuous liquid phase pre-ceramic coatings for high temperature application," Fibers and Polymers, vol. 17, no. 2, pp. 229-240, 2016.

[30] H. Huang, N. Xu, G. R. Sun, X. Yang, and J. Hu, "Improvement of oxidation resistance of carbon fibers by coating SiC," Materials Research Express, vol. 6, p. 065610, 2019.

[31] S. L. Fu, Y. X. Wang, Y. Y. Wang, C. Qu, F. X. Niu, and J. J. Liu, "A study of boron nitride coatings on carbon fibers by the powder immersion reaction method," Materials Research Express, vol. 5, p. 066421, 2018.

[32] R. I. Baxter, R. D. Rawlings, N. Iwashita, and Y. Sawada, "Effect of chemical vapor infiltration on erosion and thermal properties of porous carbon/carbon composite thermal insulation," Carbon, vol. 38, no. 3, pp. 441-449, 2000.

[33] R. I. Baxter and R. D. Rawlings, "Microstructure and solid particle erosion of carbon-based materials used for the protection of highly porous carbon-carbon composite thermal insulation," Journal of Materials Science, vol. 32, no. 17, pp. 4485-4492, 1997. 
[34] X. X. Liu, T. T. Wang, M. Y. Zhuang, B. J. Xin, and W. Liu, "Investigation of the thermal transfer behavior of single layer woven fabrics at different temperatures," Journal of Engineered Fibers and Fabrics, vol. 11, pp. 9-16, 2016.

[35] L. Kong, H. Liu, W. Cao, and L. Xu, "PAN fiber diameter effect on the structure of PAN-based carbon fibers," Fibers and Polymers, vol. 15, no. 12, pp. 2480-2488, 2014.

[36] P. W. Gibson, C. Lee, F. Ko, and D. Reneker, "Application of nanofiber Technology to nonwoven thermal insulation," Journal of Engineered Fibers and Fabrics, vol. 2, pp. 32-40, 2007. 